This is the peer reviewed final draft of the following article: Van Looy et al. 2019. The three Rs of river ecosystem resilience : Resources, recruitment, and refugia. River Research and Applications 35 (2): 107-120. which has been published in final form at https://doi.org/10.1002/rra.3396

\title{
The three Rs of river ecosystem resilience: Resources, Recruitment and Refugia
}

Short running title: The three Rs of river resilience: Resources, Recruitment and Refugia

Kris Van Looy ${ }^{1,2}$, Jonathan D. Tonkin ${ }^{3,4}$, Mathieu Floury ${ }^{2}$, Catherine Leigh ${ }^{5,6}$, Janne Soininen ${ }^{7}$, Stefano Larsen $^{8}$, Jani Heino ${ }^{9}$, N. LeRoy Poff ${ }^{10,11}$, Michael Delong ${ }^{12}$, Sonja C. Jähnig ${ }^{13}$, Thibault Datry ${ }^{14}$, Núria Bonada $^{15}$, Juliette Rosebery ${ }^{16}$, Aurélien Jamoneau ${ }^{16}$, Steve J. Ormerod ${ }^{17}$, Kevin J. Collier ${ }^{18}$, Christian Wolter $^{13}$

${ }^{1}$ Institute of Bio- and Geosciences, Research Centre Jülich, 52428 Jülich, Germany

${ }^{2}$ River Hydro-ecology Lab, Research Unit RiverLY, Irstea Centre de Lyon-Villeurbanne, Villeurbanne Cedex, France

${ }^{3}$ Department of Integrative Biology, Oregon State University, Corvallis, OR 97331, USA

${ }^{4}$ School of Biological Sciences, University of Canterbury, Christchurch 8140, New Zealand

${ }^{5}$ Science and engineering faculty, Queensland University of Technology, Gardens Point Campus, Brisbane 4000, Queensland, Australia

${ }^{6}$ Australian Rivers Institute, Griffith University, 170 Kessels Rd, Nathan 4111, Queensland, Australia

${ }^{7}$ Department of Geosciences and Geography, P.O. Box 64, FI-00014 University of Helsinki, Finland

${ }^{8}$ Idiv, German Centre of Integrative Biodiversity Research Halle-Jena-Leipzig, Deutscher PI. 5E, 04103 Leipzig, Germany

${ }^{9}$ Finnish Environment Institute, Natural Environment Centre, Biodiversity, Paavo Havaksen Tie 3, FI90570 Oulu, Finland

${ }^{10}$ Department of Biology, Colorado State University, Fort Collins, CO 80523, USA

${ }^{11}$ Institute for Applied Ecology, University of Canberra, Canberra, ACT 2617, Australia

${ }^{12}$ Department of Biology, Winona State University, Winona, USA

${ }^{13}$ Leibniz-Institute of Freshwater Ecology and Inland Fisheries, Müggelseedamm 310, 12587 Berlin

${ }^{14}$ DYNAM Lab, Research Unit RiverLY, Irstea Centre de Lyon-Villeurbanne, Villeurbanne Cedex, France

${ }^{15}$ Grup de Recerca Freshwater Ecology and Management (FEM), Department de Biologia Evolutiva, Ecologia i Ciències Ambientals, Facultat de Biologia, Institut de Recerca de la Biodiversitat (IRBio), Universitat de Barcelona, 08028 Barcelona, Catalonia, Spain

${ }^{16}$ Research Unit Aquatic Ecosystems and Global Change (EABX), Irstea Bordeaux, Cestas Cedex, France

${ }^{17}$ Water Research Institute, Cardiff School of Biosciences, Cardiff University, Cardiff, CF10 3AX, UK

${ }^{18}$ Environmental Research Institute, The University of Waikato, Hamilton, New Zealand

Corresponding author Kris Van Looy, Stationsstraat 110, 2800 Mechelen, Belgium, kris.van.looy@ovam.be 


\begin{abstract}
Resilience in river ecosystems requires that organisms must persist in the face of highly dynamic hydrological and geomorphological variations. Disturbance events such as floods and droughts are postulated to shape life history traits that support resilience, but river management and conservation would benefit from greater understanding of the emergent effects in communities of river organisms.

We unify current knowledge of taxonomic-, phylogenetic- and trait-based aspects of river communities that might aid the identification and quantification of resilience mechanisms. Temporal variations in river productivity, physical connectivity and environmental heterogeneity resulting from floods and droughts are highlighted as key characteristics that promote resilience in these dynamic ecosystems.

Three community-wide mechanisms that underlie resilience are: (1) partitioning (competition/facilitation) of dynamically varying resources; (2) dispersal, re-colonization and recruitment promoted by connectivity; and (3) functional redundancy in communities promoted by resource heterogeneity and refugia. Along with taxonomic and phylogenetic identity, biological traits related to feeding specialization, dispersal ability and habitat specialization mediate organism responses to disturbance. Measures of these factors might also enable assessment of the relative contributions of different mechanisms to community resilience.

Interactions between abiotic drivers and biotic aspects of resource use, dispersal and persistence have clear implications for river conservation and management. To support these management needs, we propose a set of taxonomic, phylogenetic and life-history trait metrics that might be used to measure resilience mechanisms. By identifying such indicators, our proposed framework can enable targeted management strategies to adapt river ecosystems to global change.
\end{abstract}

\title{
Glossary box
}

Resilience: we adopt the original definition of Holling (1973) - nowadays denoted as ecological resilience - as the amount of disturbance an ecosystem (or community) can tolerate and its capacity to reorganize before it loses its original functions. In this definition, both the resistance to and recovery after disturbance are accounted for.

Resource: here use of this term is not restricted to only food, but also encompasses elements such as light (especially for primary producers), oxygen (anoxic conditions occur in river sediments), substrate (such as bare sediment for riparian plants and ground beetles, or gravel and branches for benthic organisms) and temperature (for thermophilic organisms)

Resource pulses: strong fluctuations in availability of resources occur under pulsed disturbances of floods and droughts in river ecosystems, with consequences to biotic communities.

Resource facilitation: Facilitation is a significant ecological process that produces community-level effects through individual positive interactions. By increasing access to resources, facilitation can 
impact community structure and diversity. Such interactions are considered "mutualisms" when both species derive benefit from the interaction.

Recruitment: the processes of regeneration and recolonization that follow disturbance enabling the recovery of the biotic community.

Metacommunity dynamics: metacommunities are determined by exchanges among populations through dispersal. The strength of these exchanges can be affected by disturbances; recruitment recovery determines the rate of return to preceding exchanges.

Refugia: used here in a wider sense, i.e. sites offering (1) refuge to changing environments, and (2) continuity in environmental conditions together with habitat heterogeneity offering opportunities for speciation and specialisation. Environments with strong gradients in moisture and temperature like fluvial ecosystems are rich in micro- and macrorefugia, respectively, at site and landscape scales.

Functional redundancy: a single function can be supported by more than one species (functional equivalence of species) in a community. If one of the species is lost, the function is maintained for the ecosystem. Associated to response diversity of species, this concept immediately leads to a resilience mechanism in refugial environments characterised by heterogeneity and continuity in conditions.

\section{Introduction}

Flow-related disturbances, such as floods or droughts, are characteristic phenomena in river systems that can act as a dominant structuring force on lotic communities (Resh et al. 1988; Poff \& Ward 1989; Townsend et al. 1997; Death 2010). Some river biota can be highly resilient to such disturbances, either by resisting their effects and persisting, or by recovering rapidly following disturbance through recolonisation (Naiman et al. 2005; McCluney et al. 2014). Mechanisms of river resilience are, however, being challenged by human-caused alterations to the characteristic properties of river systems: the primacy of hydrologic disturbance regimes, dendritic network connectivity, and tightly coupled longitudinal and lateral resource flows (Oliver et al., 2015; Angeler \& Allen, 2016; Müller et al. 2016). The interplay between climate change, land-use intensification and human population growth is likely to bring new challenges to the management and conservation of freshwater ecosystems globally, highlighting the need for a better understanding of and adaptive management approaches for ecosystem resilience.

Since a disturbance is an event that disrupts ecosystem and community structure through changes in resources, habitat availability and/or environmental conditions (White \& Pickett 1985), we can identify three mechanisms for assessing ecological resilience. Floods and droughts induce fundamental disturbances to the ecosystem in three ways (Fig. 1): (i) productivity shifts rendering resources unavailable or pulsed, strongly influencing river community assembly and food webs (Uehlinger et al. 2000, Junk et al. 1989); (ii) increasing and/or interrupting physical connectivity, which has repercussions for habitat availability and metacommunity structure (McCluney et al. 2014); and (iii) altering environmental conditions, impacting habitat quality and heterogeneity, which regulate community diversity (Lake 2000, Poole 2002). These flow regime fluctuations can be seasonally predictable or irregular and unpredictable (Poff \& Ward 1989), and lead to pulse disturbances such as nutrient and sediment pulses, rapid connection-disconnection of habitats (e.g. through floodplain inundation), and extreme physicochemical conditions (e.g. highest shear forces at bank-full flows, high temperature and low dissolved oxygen at low flow). 
In contrast to natural pulse disturbances, human-induced alterations, such as flow regime alteration, pollutant inputs, climate change or habitat degradation, mostly take the character of press or ramp disturbances (increasing gradually or incrementally in intensity) in river ecosystems and their communities (Lake 2000). Human activities such as land cover modification are at the origin of shifts in the seasonality, frequency and duration of pulse disturbances, and thus challenge river resilience mechanisms. Further, the timing of disturbances may be more important than pulse magnitude in terms of effects on resilience capacity (Woodward et al. 2016; Poff et al. 2018). Floods and droughts in river systems show specific effects on resources, connectivity and habitat heterogeneity. As a result, organisms respond specifically to events, either in benefiting from resource pulses or avoiding flood disturbance by moving away, or to seek refuge in a specific niche, rather than some combination of response mechanisms (McMullen et al. 2017).

Taxonomic-, phylogenetic- and trait-based approaches have been proposed to interpret community responses to disturbance across disturbance types, levels of biological organization and multiple biogeographic regions (Cadotte et al. 2015; Kremer et al. 2016). The aim of this paper is to present a conceptual framework that enables the core mechanisms of ecological resilience - the 'three Rs' of Resources, Recruitment and Refugia - to be determined jointly and interactively at the river ecosystem and community levels. For this purpose, we (i) identify resource provision/productivity, spatial connectivity and habitat heterogeneity as the three mechanism axes related to ecosystem response to disturbance, (ii) identify resource competition/facilitation, recruitment dynamics and refugia's functional redundancy as the respective community-level mechanisms, and (iii) advise how to operationalise this concept through application of biological indices and species' life history traits, presenting three case studies that illustrate the power of the proposed framework.

\section{The three Rs conceptual framework}

The ensemble of individual species' responses to disturbance through competition/facilitation for resources, movement that avoids mortality, or persistence through adapted traits in specific niches, result in resilience at the community level through one or more of three resilience mechanisms. First, resource competition/facilitation is the mechanism for species that can take advantage of changed (either pulsed or depleted) resource conditions during disturbance. Competition and/or facilitation can occur in response to disturbance-driven resource pulses (Stachowicz 2001), resulting in a reassembled community following the disturbance. Second, recruitment recovery depends on species' abilities to move through space and time (Heino et al. 2015). This can occur either by active dispersal or by resting stages, and serves to avoid disturbance and/or rapidly recolonize afterwards. Recruitment is supported by life history traits such as high mobility and fecundity. Third, functional redundancy in refugia results in persistence of functions at the community level, and depends on the variation in responses to environmental change by species within a functional group (response diversity, Elmqvist et al. 2003). Refugia are environments characterized by heterogeneity and continuity in habitat conditions favouring increased species survival and hence functional redundancy, as more species of the same functional group will co-exist and show variation in response to disturbance. Species differ in their ability to find and use refugia, but the more heterogeneous the habitat, the more likely many species will survive (Scherrer \& Körner 2011, Keppel et al. 2012).

These types of responses thus reveal three key community resilience mechanisms related to resources, recruitment and refugia. Since they evolved over time, the prevailing mechanisms will also depend on the ecosystem's historical disturbance characteristics, which vary substantially across climatic, geologic and land-cover gradients (Rinaldi et al 2015). Thus, we assume that rivers with strong resource pulses will host communities that re-assemble more readily, while those in river 
networks with high connectivity can recover quickly through recolonization after disturbance, and rivers with high habitat heterogeneity at local and riverscape scales offer refugia that promote species persistence and functional redundancy.

\section{Resource competition/facilitation}

Resources and productivity are principal determinants of a community's recovery potential (Brown \& Williams 2015). Resource competition and facilitation are the two opposite interspecies response mechanisms to temporal resource variation. In response to resource pulses, the resilience mechanism at the community level involves internal re-organisation, i.e. reassembly, based on biotic interactions including intra- and interspecific competition and facilitation (Connell \& Ghedini 2015). Resource pulses induce trophic responses at the community level as possible compensatory effects, i.e. species' density adjustments to the new resource levels (Connell \& Ghedini 2015). When the disturbances exceed any such compensatory effects, resource scarcity or resource pulses will engender community re-organisation through resource competition and facilitation internally, or through altered external subsidies between different ecosystem compartments like the river's aquatic and terrestrial riparian zone, depending on food web interaction strength (Yang et al. 2008; Altena et al. 2016). Rivers and adjacent terrestrial ecosystems have permeable boundaries that are frequently crossed by two-way resource subsidies, e.g. from flooding, insect emergence, and vice versa, e.g. floodplain feeding by fish, leaf litter input in autumn (Larsen et al. 2016). Adaptations to both pulses and subsidies exist and are reflected in flexible timing in resource use (Holt et al. 2008).

With disturbances such as floods and droughts, resource availability and abundance can be pulsed (Yang \& Naeem 2008), leading to numerical responses at the population level (de Senerpont Domis et al. 2013; Richardson \& Sato 2015), and indirect effects through subsidies between ecosystem compartments and community functional groups (Greig et al. 2012). Functionally different groups of taxa respond differently to resource dynamics, e.g. primary producers may not be detrimentally affected by nutrient pulses but are sensitive to disturbance of light intensity. In contrast, consumers are not limited directly by light availability but depend on undisturbed, continuous organic food resource provision of suitable quality. Furthermore, species' interrelationships can shift from facilitation to competition due to interannual resource dynamics, such as change in timing and amplitude of low or high flows, or rainfall pulses (Tielbörger \& Kadmon 2000; Liancourt et al. 2012).

Table 1 presents taxonomic, phylogenetic and functional trait indices that can be used as indicators for the resilience mechanisms. For resources, taxonomic indices (Table 1), such as Shannon diversity which captures changes in species relative abundances, allow inference of community-level consequences of shifts in resource dynamics. Among the phylogenetic indices, species relatedness within a specific order or family can indicate competitive or facilitative responses to resource fluctuation. Closely related species are assumed more likely to overlap in habitat and resource use (Poff et al. 2006). Facilitation can promote phylogenetic diversity, due to longer term effects of mutualism and/or segregation (Angelini et al. 2016). Traits related to feeding habits and guilds should directly reflect changes in resource availability. Traits of trophic position (predator-prey) and strategy (detritivore-omnivore), combined with landscape and habitat specialization (niche breath and selectivity) for aquatic and terrestrial communities of river ecosystems can inform the extent to which resource competition/facilitation and subsidies influence communities and hence indicate 
their sensitivity to environmental changes (Comte et al. 2014; MacLean \& Beissinger 2017). Resource subsidies between ecosystem compartments offer resilience to environmental change and specifically to resource pulses under specific conditions of timing or periodicity. The linkage between resilience, subsidy pulses and asynchrony between different resources across ecosystems or compartments, is formulated as the subsidy-stability hypothesis (Jones \& Lennon 2015; Richardson \& Sato 2015). Both climate and land-use changes can alter the local productivity and pulsing of resources, potentially disrupting subsidy-stability (Soininen et al. 2015). The trait-based representation of these relationships allows for a better understanding of these interactions and can potentially inform adaptive resilience management (Larsen et al. 2016). Current knowledge in this domain of species interactions and food webs already offers tools for assessing strength and resilience of food web interactions (Wootton \& Emmerson 2005).

\section{Recruitment}

The recruitment mechanism of resilience relies on metacommunity dynamics based on habitat connectivity, species' dispersal abilities and size of the regional species pool. Many recent works elucidate the role of dispersal, landscape connectivity and exchange processes in the resilience of communities and ecosystems (Earn et al. 2000; Hughes et al. 2005). River network properties, such as their hierarchical dendritic structure and drainage density (Fausch et al., 2002; Benda et al., 2004, Coté et al. 2009), as well as the spatial arrangement of habitat patches across the landscape (Grant et al., 2007; Erös et al., 2012; Phillipsen \& Lytle, 2013), influence how communities are organized and respond to disturbances (Altermatt 2013a; Tonkin et al. 2018a). River network configuration may affect community structure through a variety of mechanisms that relate to the relative influence of local and regional processes (Altermatt 2013a; Altermatt 2013b; Brown \& Swan 2010). The position of a site within the network may influence the rate at which a site is recolonized post-disturbance; sites at more isolated upstream positions may receive a lower rate of recruitment following disturbances than sites at more central network positions resulting from a poorer connection to the regional species pool (Tonkin et al. 2016). Yet, the more connected downstream sites may, at the same time, be less resilient to disturbances through a greater level of spatial homogenization resulting from a stronger relative influence of mass effects compared to species sorting (Brown \& Swan 2010).

Recovery of riverine biotic communities is presumed to be largely based on dispersal capacity in metacommunities as source-sink dispersal and drift rates are particularly high in river networks (Heino et al. 2015; McCluney et al. 2014). We may expect that dispersal capacities affect recovery rates, with strong dispersers recovering rapidly depending on proximity to source areas. Specialist dispersal traits can also explain species persistence to extreme disturbance; for instance, benthic invertebrate taxa with mobile larvae and/or terrestrial adult stages prove significantly more resilient to extreme events (Poff et al 2018). In addition to dispersal, some species may also form seedbanks or resting stages that survive unsuitable periods (e.g. floods or drought-induced drying) inside the sediments. This can be understood as 'temporal dispersal' or 'travelling in time', observed for both riparian plants (Honnay et al. 2009) and aquatic invertebrates in intermittent rivers (Stubbington \& Datry, 2013) or floodplain soils (Catlin et al. 2017). The traits of resting and dispersal stages will determine the rate of community recovery following disturbance. For example, if species' dispersal abilities are poor, recovery may be comparatively slow, and the associations between environmental conditions and community structure become weak (dispersal limitation). On the other hand, if species have strong dispersal abilities, recovery may be faster, and community structure is strongly affected by high dispersal rates through mass effects. Stronger dispersing lotic invertebrates, for 
example, tend to have more similar communities among sites in river networks than their weaker dispersing counterparts (Thompson \& Townsend, 2006; Leigh \& Datry 2017, Datry et al. 2016a), suggesting a greater ability to recover rapidly following local disturbances. However, recovery rate will also depend on whether invertebrates disperse most strongly by air (e.g. as flying adults) or water (e.g. by drift), with out-of-channel dispersal by air across river reaches and drainage divides being associated with more similar communities among rivers at the landscape scale (Datry et al. 2016b; Leigh \& Datry 2017). Recruitment recovery can optimally be measured at the network level, over adjacent sites with a measure of community similarity (beta diversity, Table 1). The capacity for movement or survival to enable recovery is a strongly structuring phylogenetic aspect driven by ecosystem (dynamics) characteristics, measurable as community phylogenetic similarity (Tedesco et al. 2012).

Through their greater connectivity, downstream locations may be more influenced by mass effects (i.e. high dispersal rates from favourable 'source' to unfavourable 'sink' localities; Pulliam 1988) than more isolated headwaters (Brown \& Swan 2010), and thus be more resilient through stronger recruitment recovery. In contrast, species sorting should be stronger in headwaters, because high dispersal rates typical of mainstems do not interfere with local dynamics in the headwaters (Grönroos et al. 2013; Brown \& Swan 2010). This is especially true for benthic invertebrate communities that appear highly influenced by connectivity to upstream parts (i.e. sources for drift dispersal) (Göthe et al. 2013). By contrast, fish community response to disconnection is mostly determined by local conditions in combination with barriers to dispersal in downstream sections (Van Looy et al. 2014). For passively yet efficiently dispersed mobile benthic diatoms, environmental filtering is considered to play a primary role in structuring metacommunities, although the influence of mass effects and dispersal limitation on community structure has also been highlighted in relation to connectivity at larger spatial scales (Bottin et al. 2016).

Since the recruitment recovery of riverine biota after disturbance is presumed to be largely based on dispersal capacity and connectivity within and between river networks, the dispersal traits (functional traits, Table 1) of organisms and the physical connectivity of the landscape should interact to moderate resilience (Heino et al. 2017; Tonkin et al. 2018a). This interaction may be speciesspecific with respect to dispersal routes and dispersal rates. For example, even if diatom species dispersal is primarily passive, their metacommunity dynamics appear to be under both local and regional connectivity control, in relation to flow disturbance regimes (Biggs 1995; Göthe et al. 2013; Dong et al. 2016; Soininen et al. 2016).

In addition to dispersal capabilities, reproduction traits foster recruitment and recovery after disturbances. Life history traits promoting regeneration comprise high fecundity with the production of many eggs or seeds and seed banks. For fish, multiple spawning (iteroparity) or batch-spawning in combination with a protracted spawning season insure successful reproduction at broad ranges of environmental fluctuations.

\section{Refugia}

Habitat heterogeneity is generally acknowledged to provide ecological resilience to communities through the functional redundancy mechanism driven simultaneously by organisms' response diversity and habitat specialization (Angeler \& Allen 2016). Functionally similar organisms that respond differently to disturbances will sustain the structure and function of communities in space and time (Nash et al. 2016). Community resilience can result from compensatory interactions among 
species in response to environmental fluctuations (Peterson et al. 1998; Angeler \& Allen 2016). Fluctuations in the abundances of species with different adaptive modes to disturbance may be one mechanism stabilizing community function in a varying environment (McNaughton 1977), and interannual fluctuations of species with broad environmental tolerances another.

Most resilience literature puts forward functional redundancy as the principal mechanism by which communities persist through disturbances (Angeler \& Allen 2016). The response to disturbance is determined in species habitat-specific resistance and resilience mechanisms that are generally described with life history traits that promote survivorship, such as behavioral and morphological traits (e.g. Lytle \& Poff 2004). The mechanism behind functional redundancy is the functional similarity of species in one trait, but their speciation or conditional differentiation in others.

The role of landscapes as refugia is ruled by local and riverscape scale environmental heterogeneity, together with the continuity of provision of a habitat mosaic under changing environmental conditions (Scherrer \& Körner 2011, Keppel et al. 2012). River ecosystems offer refugia from disturbance through a mosaic of habitat patches that confer habitat heterogeneity and promote specialization of organisms (Townsend \& Hildrew 1994). The redundancy response to disturbance is most directly indicated by taxonomic richness (Table 1 ) - under this mechanism vulnerable species are lost to disturbance but afterwards species richness recovers via recolonization during more 'stable periods' (Leigh et al. 2016). The changes in taxonomic richness correspond to a constant functional diversity under the functional redundancy mechanism. The continuity and habitat heterogeneity characteristics of refugia should also result in high and persistent phylogenetic distinctness and diversity indicating the longer term community composition impact of the river's disturbance regime.

\section{Specific functional traits per resilience mechanism for different biotic groups}

For the three R-mechanisms, we can identify specific functional traits and levels of community organisation. Understanding how communities are shaped by abiotic and/or biotic factors has been an enduring theme in ecology, for example, by analysing species coexistence, species traits and evolutionary relatedness (Webb et al., 2002; Cavender-Bares et al., 2004; Kraft et al., 2007; Múrria et al., 2012; Dijkstra et al., 2014). In general, species acquire traits and diverge through evolution and selection, and are subsequently filtered from the regional pool through abiotic and biotic factors that act on traits (Webb et al. 2002, Saito et al. 2016). In river ecosystems, floods and droughts are thought to be the major drivers of community organization and resilience (Resh et al., 1988; Lytle \& Poff, 2004; Death, 2010). Such events indeed can act as strong abiotic filters that might select for specific traits, resulting in functional and phylogenetic clustering of closely related species that have similar traits matching the requirements of their environment (i.e. what is good for one species will be good for closely-related species) (Kraft et al., 2007; Gerhold et al. 2015; Saito et al., 2016). The traits fostering resilience should be beneficial and thus conserved in river systems, because they have evolved in disturbance-dominated (i.e. flowing) systems. Tolerant, large-bodied taxa may be resistant - some may withstand the variation in currents and also tolerate variation in chemistry, while smallbodied taxa may not be resistant but recover rapidly due to short generation times. In addition to size, the shape and ability to resist flow also affects recovery ability. Taxa with high dispersal and regeneration capacity recover fast from disturbances if colonists remain available in the local or 
regional species pools. The incorporation of phylogeny and evolutionary information into functionaltrait-based approaches is one way to understand responses to disturbance.

Many functional trait metrics and indices of disturbance response exist. In fish, for instance, responses to fluctuations of resources have been observed in batch spawning and extended spawning seasons, while for recruitment recovery high fecundity promotes resilience (Table 2). By contrast, multiple spawnings per year increase the probability at least some of the offspring will encounter favourable environmental conditions (Wolter et al. 2015). For benthic invertebrates, mobility by larvae, high drift rates or a hard exoskeleton (or shell) can provide resistance to flow disturbances (Poff et al 2018). Further, mobility of all stages is seen as a recovery mechanism to both droughts (Leigh \& Datry 2017) and floods (Woodward et al. 2016; Poff et al. 2018). Dispersal through drift, swimming and adult flight ability implies important functional traits in this regard. With disturbance, associated resource pulses/fluctuations should mean generalist species with high fecundity and short life-cycles (multivoltine) have more chances in re-colonisation. The refugia and redundancy mechanism, on the other hand, should be promoted by the presence of specialists, like those species that have strategies of oviposition by aerial adults, or survive with buried eggs or under anoxic conditions. The nature of the disturbance regime (magnitude, frequency, timing) of individual streams will result in different expectations of which 'mechanism' is dominant based on the local spatio-temporal dynamics. For plants, Grime (1974) introduced the C-S-R strategy triangle to classify species according to their response to stress and disturbance. Competitors (" $\mathrm{C}$ ") respond strongly to the resource conditions and pulses to survive stress and disturbances at the expense of other species in the community; ruderals (" $R$ ") have strategies for quick recruitment and recovery after disturbance (like many seeds/long-lived seed banks or strong resprouting roots); and stress tolerantresistant (" $\mathrm{S}$ ") specialist species are adapted to the disturbance, or present in specific undisturbed niches.

\section{Framework to assess ecosystem resilience in management perspective}

To be applicable in river management, the recognition of the three $\mathrm{R}^{\prime} \mathrm{s}$ and their quantitative assessment with the presented indices requires a framework to infer how the mechanisms described above contribute to community resilience.

The framework in Figure 2 shows the three mechanisms as axes that can be used to measure the strength of resilience, and the arrows highlight the external drivers of specific community resilience mechanisms. Strong resource dynamics drive organisms to resource competition or facilitation; high connectivity allows dispersal and re-colonization; and increasing habitat heterogeneity promotes species survivorship and functional redundancy. Hence, community composition as reflected in the prevailing traits indicates the relative contribution of the three specific mechanisms, and thus can indicate a community's potential sensitivity and resilience to specific types of disturbance. A community with a majority of good dispersing species, for example, might be vulnerable to strong resource pulses, while a community with many trophic or habitat specialists might be vulnerable to changes in ecosystem connectivity or changes in resource dynamics, which might provide opportunities for generalists to dominate. This framework can be applied to measure the community resilience over the three axes, as illustrated in Figure 3 for the example of the lost resilience of the Upper Mississipi River with the river regulation mid-20 th century (example 2 in the box). In this example, the variance of trophic position of fish guilds indicates the functional diversity for the 
Refugia mechanism. Measured in 'decadal trophic position diversity', we observe a strong decrease along the Refugia axes. In the resulting resilience surface, Recruitment also diminished slightly through partial loss of connectivity by the lock-and-dam construction (loss of diadromous fish species), and Resources increased slightly through the increase in peaks of algal blooms due to flow regulation.

In this way, the framework can also inform possible management interventions aimed at river resilience. For Resource dynamics, communities characterised by resource resilience traits indicative of specific resource dynamics can be managed around 'constraining' or restoring resource pulses and fluctuations, while preserving heterogeneity and connectivity. For Recruitment recovery, for communities dominated by species with high dispersal capacities, management should focus on preserving well-connected systems (removing barriers/obstacles for dispersal). Where poor dispersal abilities dominate at the community level connections should focus primarily on lateral connectivity with floodplain habitats. Finally, for Refugia, communities with many habitat specialists can be preserved by maintaining habitat heterogeneity and managing for environmental quality conditions (even for extreme conditions such as in alpine streams).

Through the identification of the specific traits of the extant community, the predominant resilience mechanism at the community level can be determined. Consequently, we postulate that the three resilience mechanisms (resources, recruitment and refugia) are complementary and interact with landscape/ecosystem characteristics, as represented in a three-dimensional framework (Figure 2). The conceptual framework in Figure 2 can help guide the assessment and prediction of patterns of community changes in response to prevailing extrinsic drivers, and resilience in response to environmental disturbances.

The listed indices in Tables 1 and 2 are a selection of generally acknowledged resilience traits or indices. Many more examples exist of specific resilience traits and trait-based indices of specific disturbances in rivers such as drought (Chessman 2009), flow intermittence (Leigh \& Datry 2017), floods (Poff et al. 2018), sedimentation (Glendell et al. 2013), or pollution (Liess \& Beketov 2011). Here, we emphasize the application of a variety of taxonomic, phylogenetic and functional traits, to be able to capture the prevailing mechanism. Prevalence of resilience mechanisms at the community-level will depend on population density and resources (Weaver et al. 1996; Oliver et al. 2015); connectivity and dispersal ability ranging from fine-scale migration (e.g. organisms moving into interstitial spaces of a river bed) to regional scale dispersal (e.g. organisms moving over long distances for reproduction) (Pedersen et al. 2016); and landscape heterogeneity and refugia availability (Nimmo et al. 2015; Pyne \& Poff 2017). Responses to and the relative importance of mechanisms operating at the community level will also vary with the severity and predictability of the disturbance (Dong et al. 2017; Tonkin et al. 2017). Accordingly, relative changes of trait composition at the community level might offer strong indications of the dominant mechanisms and the strength of community resilience to specific disturbances.

Box Examples of application of taxonomic, phylogenetic and functional trait indices to assess resilience 


\section{Example 1. Need for multiple indices to reflect different mechanisms}

The trait-based approaches to appraise the mechanisms behind community resilience can be illustrated using a case-study from the Lynn Brianne Stream Observatory (Wales, UK: see Ormerod \& Durance 2009). A long-term time-series of benthic invertebrate communities monitored in multiple catchments shows overall stability in taxonomic richness and suggests resilience to environmental changes (Larsen et al. 2018). Different responses to environmental change can be inferred from taxonomic and phylogenetic indices (respectively taxonomic richness and taxonomic distinctness, Fig. 4) because the two metrics show specific variations that can each be linked to specific types of environmental change, involving large flow variations and high temperatures.

Taxonomic richness appears more sensitive to the large variations in discharge preceding the spring of 1993, whereas taxonomic distinctness responded more strongly to low flows coupled with the European heat wave in 2003. This might be due to the specific selection effect of increased water temperature that filters out sensitive taxa, thus lowering community distinctness. Conversely, unstable flows in 1993 presumably removed a wide range of species non-selectively to taxonomic affiliation (thus lowering overall richness but not distinctness). Detailed functional trait-based approaches might further help to understand the mechanisms that allow species to withstand specific disturbances and how their responses scale up at the community level (cfr. Woodward et al. 2016). In this case, detailed information on the ability of species to resist flow variations (e.g. higher mobility that allows organisms to move to favourable microhabitats) and drought (e.g. more efficient respiration enables survival with lower dissolved oxygen concentration), could provide important additional insights.

In this case study, a measure of taxonomic richness can indicate the community response in redundancy most clearly, where the phylogenetic diversity provided a strong indicator for recruitment recovery and for selective responses (specialists resistant to heat-wave). In conclusion, most studies find that responses are difficult to reveal with single indices, and that community-level aspects of niche breath and specialization often are necessary to analyse over longer time intervals to fully detect and interpret responses of communities to disturbances (Larsen et al. 2018).

\section{Example 2. Resilience lost in the regulated Mississippi River due to diminishing temporal and spatial heterogeneity}

A major change in the riverine landscape of the Upper Mississippi River occurred in 1935 - 1939 with the construction of locks and dams that stabilized summer water levels to maintain a navigable channel during the summer. Applied to a 120 -yr period encompassing both the pre-dam and postdam phases, a trait-based analysis detected functional changes in communities based on trophic position and feeding traits of fish, mussels, and snails. Carbon and nitrogen stable isotope ratios were used to calculate trophic position of fish feeding guilds, revealing marked variation in trophic position in response to hydrological conditions during the pre-dam period, whereas reduced variation in trophic position was evident during the post-dam period (Fig. 5). In essence, the functional diversity of the communities - observed as variation of trophic position - diminished after 1940 with completion of the lock and dam system, even during periods of both high and low discharge. This loss of resilience identified in loss of functional diversity over the years, is likely a result of changes in niche space, particularly in areas immediately above each dam where habitat heterogeneity has been greatly diminished. Also, changes in resource availability are a contributing factor. Where large shifts in the contribution of benthic and pelagic resources supporting the food web characterized the predam period, this variance was lost with the diminished hydrological variability following the flow modification (Delong et al. 2011, Delong \& Thoms 2016). Managing for restoring the ecosystem's resilience should consider allowing for some degree of flow fluctuation to restore the resource pulses and shifts, and at the same time the 'original' habitat heterogeneity. Traditionally, most 
recommendations on dam impact remediation orient to resolving disrupted connectivity. The broader trait-based orientation, proposed in our framework, revealed that resources and habitat heterogeneity are the main drivers to community resilience and should be a key focus of management.

\section{Example 3. Resources partitioning response to climatic disturbance over large spatial scales}

The trophic responses of communities to environmental variation can be measured as changes in specific feeding strategies and ratios (e.g. predator-prey), or in composite indices of specialization for feeding strategies and feeding habits, highlighting different resilience mechanisms related to resource provision and pulses. As a case study, analysis of long-term data throughout France has revealed how benthic invertebrates have recovered from decades of water pollution and responded to recent temperature increase, via resource partitioning leading to trophic amplification, i.e. the intensification of trophic interactions and pathways through the food web (Van Looy et al. 2016; Floury et al. 2018). This has led to strong responses in community traits related to feeding specialization (measured with a composite trait-based index for specialization in feeding strategies and feeding habits), phosphate reduction (presumably reduced periphyton biomass) and climate warming, that can be described from a more detailed regional scale analysis of feeding specialization for the period 1992-2012 (Fig. 6).

A first mechanism (upper sector in Fig. 6) reflects long-term increases in feeding specialization resulting from moderate environmental changes (i.e. warming) in the absence of marked changes in resources (i.e. phosphate concentration). This is the most common case of active resource partitioning that corresponds to the trophic amplification processes where resources are likely to be non-limiting, allowing moderate temperature increases to enhance productivity and promote specialists for different resource types (e.g. Yvon-Durocher et al., 2015). Conversely, two mechanisms of limitation - associated with little resilience - resulted where either resources (left sector in Fig. 6) or warming (right sector in Fig. 6) were likely to limit specialist organisms. In both cases, conditions would provide too few resources because nutrient availability and temperature gain were either too weak or too strong to enhance productivity. Finally, the strongest reduction in phosphates allowed the recovery of vulnerable species (bottom sector in Fig. 6) as well as significant increase (recovery) in the proportion of feeding specialists (see Floury et al., 2013). Consistently with the nationally observed trends, most of the sites studied (c. 70-80\%) tended to follow the first mechanism, supporting a predominant effect of trophic amplification.

This case study shows how resilience over large spatial and temporal extents can reflect trophic changes controlling long-term biodiversity patterns and responses to environmental change. While these observations are sometimes counterintuitive in the global warming context, they reveal how trophic processes can provide insurance against biodiversity loss while underpinning ecosystem resilience (Peterson et al., 1998; Mori et al., 2013). It underscores that resource pulses increase resilience for non-resource limited systems, for which the reduced resource competition can apparently increase food web complexity and functional diversity. Such a conclusion, together with the role of resource pulses to subsidies and food web stability in river ecosystems, puts forward a 
strong emphasis on temporal resource dynamics in management for resilience and adaptation to global changes.

\section{Needs \& future directions}

For the proposed trait indices of Tables 1 and 2 to be adopted by environmental managers as resilience indicators, the ranges, boundaries and projected responses under disturbances for specific environmental conditions need to be determined. For specific conditions, specific rules and indicator values will apply. For example, abundant generalist species might be very resilient under frequent disturbances, but recover less after an extreme event; therefore, community resilience will depend on the initial abundance of generalists. This rule might apply differently, however, for large and small rivers. Thus, while we have offered a framework to identify the relative importance of different resilience mechanisms, to truly assess the effective strength of resilience, and the specific management options to preserve resilience and thus ecosystem functions and services, a more detailed analysis of environmental conditions and community assets will still be necessary. The signals apparent at the level of communities will depend on whether we focus on taxonomic, phylogenetic or trait data. It might also be that different time scales operate for different indices in the form of shorter-term functional responses (ecological tolerance), mid-term taxonomic responses and longer-term phylogenetic responses.

Tipping points are often searched for in resilience indicators, to determine the critical change from one ecosystem state to another (Scheffer et al. 2015). The highly dynamic nature of natural river ecosystems and their pulsed hydrologic disturbances makes the presence of alternative stable states implausible (Lake 2000), rather they exist on a continuum of states in response to antecedent flow conditions. On the other hand, anthropogenically altered flow regimes, patch and habitat dynamics, pollutant input or resource depletion can be expected to initiate tipping points. Indications for such tipping points have been observed at the scale of the river section in large rivers with artificial embankments causing significant declines in indicators of community diversity (Wolter \& Vilcinskas 1997, Van Looy et al. 2008). Moreover, human modified flow regimes have been predicted to induce threshold changes to riparian ecological network properties under future settings (Tonkin et al. 2018b). Thus, while unmodified rivers are unlikely to experience alternative stable states, modified ones may be more likely to do so (Hilton et al. 2006). Human induced pulse disturbances might furthermore be better buffered in river systems than press disturbances. Correspondingly, increased frequency of extreme events associated with climate change might be better buffered due to the pulsed nature of such events than, for example, land use changes (=press or ramp disturbances) (e.g. Woodward et al. 2016). The degree to which evolved resilience to pulse disturbances supports communities under human-induced ramp and press disturbances, must therefore also be determined.

On the other hand, high temporal variation and habitat heterogeneity induced by unpredictable flow dynamics may offer a "portfolio effect" - asynchronous dynamics across patches that reduce broadscale ecological variability - resulting in enhanced resilience (McCluney et al. 2014). The strength of these portfolio effects and metacommunity dynamics, depending on species dispersal traits, river network connectivity and habitat heterogeneity, is another field for future research as it determines the resilience of river communities to natural and anthropogenic disturbances, including climatic changes (Campbell et al. 2015; McCluney et al. 2014). 
Functional diversity of communities is proposed as a general measure for biodiversity insurance and resilience (Angeler \& Allen 2016). Still, much uncertainty remains for scale sensitivity and issues of functional diversity measurement and meaning. The same difficulty arises for phylogenetic measures. Some traits that confer resilience to extreme flow variations are not always phylogenetically conserved. For example, the ability to fly long distances as an adult insect is phylogenetically conserved, while voltinism or size at maturity are more labile insect traits (Poff et al., 2006). Similarly, certain traits indirectly related to resilience are not conserved phylogenetically, such as feeding habits or the type of locomotion (Poff et al., 2006; Pauls et al., 2008). Labile traits may be more directly related to the environment than non-labile traits (Poff et al., 2006; Verberk et al., 2013; Saito et al. 2016), which in turn suggests that labile traits are better indicators of resilience than phylogenetically conserved traits, at least when considering multiple-trait analysis. In this respect, we have to consider the limits to using phylogenetic and evolutionary information in trait-based approaches of community resilience. The integrated assessment of taxonomic, phylogenetic and functional traits may thus prove more informative than using one class of metrics alone (see also Example 1 above). For instance, in some studies from river systems phylogenetic diversity facilitated identification of specific response capacities to climate change, information that was not provided by measures of functional diversity alone (Blanchet et al. 2014; Comte et al 2014).

\section{Conclusion}

A framework is proposed to operationalize resilience research into management applications. The constraints that natural and anthropogenic disturbances place on species persistence, species pools and dispersal have considerable implications for what actions are targeted when, and where to maintain and restore lotic systems. Conservation and restoration outcomes depend on the responsiveness of the biotic community to disturbance regimes, pulses in resources, habitat patch mosaics and connectivity, the availability and quality of refugia, and the regional species pool (Tonkin et al. 2014), with heavily degraded regional species pools likely to have low resilience to habitat degradation (Stoll et al. 2016). Alternatively, strong potential to withstand changes have been documented in river networks for fish (Radinger et al. 2017), and there are examples of strong recovery after improvement of water quality for river invertebrates (Van Looy et al. 2016) and diatoms (Morin et al. 2012) due to the influence of the regional species pools and habitat connectivity. River management and restoration projects should thus focus on the entire species pool, metacommunity and habitat mosaic dynamics, and underlying network connectivity and resource dynamics, rather than on monitoring the dynamics of local communities only.

The conceptual framework presented here, together with the examples for assessing resilience mechanisms and community responses, contribute to better understanding and managing for resilience in river ecosystems. The framework has the capacity to inform river managers of how responsive or vulnerable communities and ecosystems might be to human induced disturbances.

\section{Acknowledgements}

SCJ was funded through the "GLANCE" project (Global Change Effects in River Ecosystems; 01 LN1320A) supported by the German Federal Ministry of Education and Research (BMBF) and further acknowledges the "AQUACROSS" project (Knowledge, Assessment, and Management for AQUAtic Biodiversity and Ecosystem Services aCROSS EU policies; 642317) supported by the European Union's Horizon 2020 Programme for Research, Technological Development and Demonstration. Basic ideas have been discussed in the resilience working group of the International Society for River Science (ISRS). 


\section{References}

Altena C., Hemerik L. \& Ruiter P.C. (2016). Food web stability and weighted connectance: the complexity-stability debate revisited. Theoretical Ecology, 9, 49-58.

Altermatt F (2013a). Diversity in riverine metacommunities: a network Perspective. Aquat Ecol (2013) 47:365-377 DOI 10.1007/s10452-013-9450-3

Altermatt F, Seymour M, Martinez N (2013b) River network properties shape a-diversity and community similarity patterns of aquatic insect communities across major drainage basins. J Biogeogr. doi:10.1111/jbi.12178

Angeler D.G. \& Allen C.R. (2016). Quantifying resilience. Journal of Applied Ecology, 53, 617-624.

Angelini, C. et al. (2016). A keystone mutualism underpins resilience of a coastal ecosystem to drought. Nat. Commun. 7:12473 doi: 10.1038/ncomms12473

Angermeier P.L. (1995). Ecological attributes of extinction-prone species: loss of freshwater fishes of Virginia. Conservation Biology, 9, 143-158.

Benda, L.E.E., Poff, N.L., Miller, D., Dunne, T., Reeves, G., Pess, G. \& Pollock, M. (2004) The network dynamics hypothesis: how channel networks structure riverine habitats. BioScience, 54, $413-$ 427.

Biggs B.J. (1995) The contribution of flood disturbance, catchment geology and land use to the habitat template of periphyton in stream ecosystems. Freshwater Biology 33, 419-438.

Bilton, D.T., Freeland, J.R. \& Okamura, B. (2001) Dispersal in freshwater invertebrates. Annual Review of Ecology and Systematics, 32, 159-181.

Blanchet S., Helmus M.R., Brosse S. \& Grenouillet G. (2014). Regional vs local drivers of phylogenetic and species diversity in stream fish communities. Freshwater Biology, 59, 450-462.

Bottin M., Soininen J., Alard D. \& Rosebery J. (2016) Diatom Co-occurrence Shows Less Segregation than Predicted from Niche Modeling. PLOS ONE 11, e0154581.

Brown BL, Swan CM (2010) Dendritic network structure constrains metacommunity properties in riverine ecosystems. J Anim Ecol 79:571-580. 
Brown J. H., Ernest S.K.M., Parody J M., J P. Haskell (2001) Regulation of diversity: maintenance of species richness in changing environments. Oecologia 126:321-332DOI $10.1007 / \mathrm{s} 004420000536$

Brown, E.D. \& Williams, B.K. (2015). Resilience and Resource Management. Environmental Management, 56, 1416-1427.

Cadotte M.W., Arnillas C.A., Livingstone S.W. \& Yasui S.-L.E. (2015). Predicting communities from functional traits. Trends in Ecology \& Evolution, 30, 510-511.

Campbell RE, Winterbourn MJ, Cochrane Ta, McIntosh AR (2015) Flow-related disturbance creates a gradient of metacommunity types within stream networks. Landscape Ecology 30:667-680.

Catlin, A. K., Collier, K. J., and Duggan, I. C. (2017). Zooplankton generation following inundation of floodplain soils: effects of vegetation type and riverine connectivity. Marine and Freshwater Research 68, 76-86.

Cavender-Bares, J., Ackerly, D.D., Baum, D.A., Bazzaz, F.A., 2004. Phylogenetic overdispersion in Floridian oak communities. The American Naturalist, 163, 823-843.

Chessman B. 2009. Climatic changes and 13-year trends in stream macroinvertebrate assemblages in New South Wales, Australia. Global Change Biology 15: 2791-2802.

Comte L, Murienne J \& Grenouillet G. 2014. Species traits and phylogenetic conservatism of climateinduced range shifts in stream fishes. Nature Communications DOI: 10.1038/ncomms6053.

Connell, S.D. \& Ghedini, G. (2015). Resisting regime-shifts: the stabilising effect of compensatory processes. Trends in Ecology \& Evolution, 30, 513-515.

Coté D, Kehler DG, Bourne C, Wiersma WF (2009) A new measure of longitudinal connectivity for stream networks. Landscape Ecol 24:101-113.

Culp, J. M., D. G. Armanini, M. J. Dunbar, J. M. Orlofske, N. L. Poff, A. I. Pollard, A. G. Yates, and G. C. Hose. 2011. Incorporating traits in aquatic biomonitoring to enhance causal diagnosis and prediction. Integrated environmental assessment and management 7:187-197. 
Datry T., Melo A.S., Moya N.B., Zubieta J., De la Barra E., Oberdorff T. 2016a. Metacommunity patterns across three Neotropical catchments with varying environmental harshness. Freshwater Biology 61: 277-292.

Datry, T., Bonada, N. \& Heino, J. (2016b) Towards understanding the organisation of metacommunities in highly dynamic ecological systems. Oikos 125: 149-159.

de Senerpont Domis LN, Elser JJ, Gsell AS, Huszar VLM, Ibelings BW, Jeppesen E, Kosten S, Mooij WM, Roland F, Sommer U, Van Donk E, Winder M, Lürling M 2013. Plankton dynamics under different climatic conditions in space and time. Freshwater Biology 58, 463-482 DOI: 10.1111/fwb.12053

Death, R.G., (2010). Disturbance and riverine benthic communities: what has it contributed to general ecological theory? River Research and Applications, 26, 15-25.

Delong M., Thorp, J.H., Thoms, M., McIntosh L. 2011. Trophic niche dimensions of fish communities as a function of historical hydrological conditions in a Plains river. River Systems: Integrating landscapes, catchment perspectives, ecology, management 19(3):177-187. DOI: 10.1127/1868-5749/2011/019-0036

Delong, M. D., and M. C. Thoms (2016). Changes in the trophic status of fish feeding guilds in response to flow modification, J. Geophys. Res. Biogeosci., 121, 949-964, doi: 10.1002/2015JG003249.

Dijkstra, K.D.B., Monaghan, M.T., Pauls, S.U., 2014. Freshwater biodiversity and aquatic insect diversification. Annual Review of Entomology, 59, 143-163.

Dong X, Lytle DA, Olden JD, Schriever TA, Muneepeerakul R (2017) Importance of neutral processes varies in time and space: Evidence from dryland stream ecosystems. PLoS ONE 12(5): e0176949. https://doi.org/10.1371/journal.pone.0176949

Dong X., Li B., He F., Gu Y., Sun M., Zhang H., et al. (2016) Flow directionality, mountain barriers and functional traits determine diatom metacommunity structuring of high mountain streams. Scientific Reports 6.

Earn, D.J.D., Levin, S.A. \& Rohani, P. 2000. Coherence and Conservation. Science, 290, 1360-1364.

Elmqvist T., Folke C., Nyström M., Peterson G., Bengtsson J., Walker B. and Norberg J. 2003, Response diversity, ecosystem change, and resilience. Frontiers in Ecology and the Environment, 1, 488-494. 
Erös, T., Olden, J., Schick, R., Schmera, D. \& Fortin, M.-J. (2012) Characterizing connectivity relationships in freshwaters using patch-based graphs. Landscape Ecology, 27, 303-317.

Fausch, K.D., Torgersen, C.E., Baxter, C.V. \& Li, H.W. (2002) Landscapes to riverscapes: bridging the gap between research and conservation of stream fishes. BioScience, 52, 483-498.

Floury M, Usseglio-Polatera P, Férreol M, Delattre C, Souchon Y. 2013. Global climate change in large European rivers: long-term effects on macroinvertebrate communities and potential local confounding factors. Global Change Biology 19: 1085-1099.

Floury, M., Souchon, Y. and Van Looy, K. (2018), Climatic and trophic processes drive long-term changes in functional diversity of freshwater invertebrate communities. Ecography 41:209218.

Gerhold, P., Cahill, J.F., Winter, M., Bartish, I.V., Prinzing, A., 2015. Phylogenetic patterns are not proxies of community assembly mechanisms (they are far better). Functional Ecology, 29, $600-614$

Grant EHC, Lowe WH, Fagan WF (2007) Living in the branches: population dynamics and ecological processes in dendritic networks. Ecol Lett 10:165-175

Greig, H.S., P. Kratina, P.L. Thompson, W.J. Palen, J.S. Richardson \& J.B. Shurin. 2012. Warming, eutrophication, and predator loss amplify subsidies between aquatic and terrestrial ecosystems. Global Change Biology 18: 504-514

Grime JP. 1974. Vegetation classification by reference to strategies. Nature 250: 26-31.

Grönroos, M., Heino, J., Siqueira, T., Landeiro, V.L., Kotanen, J. \& Bini, L.M. (2013) Metacommunity structuring in stream networks: roles of dispersal mode, distance type and regional environmental context. Ecology and Evolution 3: 4473-4487.

Göthe E., Angeler D.G. \& Sandin L. (2013) Metacommunity structure in a small boreal stream network. The Journal of Animal Ecology 82, 449-458.

Heino, J., Alahuhta, J., Ala-Hulkko, T., Antikainen, H., Bini, L.M., Bonada, N., Datry, T., Erős, T., Hjort, J., Kotavaara, O., Melo, A.S. \& Soininen, J. (2017) Integrating dispersal proxies in ecological and environmental research in the freshwater realm. Environmental Reviews 25: 334-349. 
Heino, J., Melo, A.S., Siqueira, T., Soininen, J., Valanko, S. \& Bini, L.M. (2015) Metacommunity organisation, spatial extent and dispersal in aquatic systems: patterns, processes and prospects. Freshwater Biology 60: 845-869.

Hilton, J., O'Hare, M., Bowes, M.J. \& Jones, J.I. (2006). How green is my river? A new paradigm of eutrophication in rivers. Science of The Total Environment, 365, 66-83.

Holling, C. S. 1973. Resilience and stability of ecological systems. Annual review of Ecology and Systematics 4:1-24.

Holt, R. D. (2008). Theoretical perspectives on resource pulses. Ecology, 89,671-681

Honnay, O., Jacquemyn, H., Van Looy, K., Vandepitte, K. \& Breyne, P. 2009. Temporal and spatial genetic variation in a metapopulation of the annual Erysimum cheiranthoides on stony river banks. Journal of Ecology 97, 131-141.

Hughes, T.P., Bellwood, D.R., Folke, C., Steneck, R.S. \& Wilson, J. (2005). New paradigms for supporting the resilience of marine ecosystems. Trends in Ecology \& Evolution, 20, 380-386.

Isaak DJ, Young MK, Luce CH et al. (2016) Slow climate velocities of mountain streams portend their role as refugia for cold-water biodiversity. Proceedings of the National Academy of Sciences, $113,4374-4379$

Jones, S. E. and Lennon, J. T. (2015) A test of the subsidy-stability hypothesis: the effects of terrestrial carbon in aquatic ecosystems. Ecology, 96: 1550-1560. doi:10.1890/14-1783.1

Junk, W.J., Bayley, P.B., Sparks, R.E., 1989. The flood pulse concept in river floodplain systems. Can. Spec. Publ. Fish. Aquat. Sci. 106, 110-127

Keppel, G., Van Niel, K.P., Wardell-Johnson, G.W., Yates, C.J., Byrne, M., Mucina, L. et al. 2012. Refugia: identifying and understanding safe havens for biodiversity under climate change. Global Ecology and Biogeography, 21, 393-404.

Kraft, N.J., Cornwell, W.K., Webb, C.O., Ackerly, D.D., 2007. Trait evolution, community assembly, and the phylogenetic structure of ecological communities. The American Naturalist, 170, 271-283. 
Kremer C.T., Williams A.K., Finiguerra M., Fong A.A., Kellerman A., Paver S.F., Tolar B.B. \& Toscano B.J. (2016). Realizing the potential of trait-based aquatic ecology: New tools and collaborative approaches. Limnology and Oceanography, n/a-n/a.

Lake PS 2000, 'Disturbance, patchiness, and diversity in streams', Journal of the North American Benthological Society, vol.19, pp. 573-592.

Lake PS 2003, 'Ecological effects of perturbation by drought in flowing waters', Freshwater Biology, vol. 48, pp. 1161-1172.

Larsen S, Muehlbauer JD, Marti E. 2016. Resource subsidies between stream and terrestrial ecosystems under global change. Glob Chang Biol 22:2489-2504.

Larsen, S. , Chase, J. M., Durance, I. and Ormerod, S. J. (2018), Lifting the veil: richness measurements fail to detect systematic biodiversity change over three decades. Ecology. . doi:10.1002/ecy.2213

Leigh, C. and Datry, T. (2017), Drying as a primary hydrological determinant of biodiversity in river systems: a broad-scale analysis. Ecography 40: 487-499. doi:10.1111/ecog.02230

Leigh, C., Bonada, N., Boulton, A. J., Hugueny, B., Larned, S. T., Vander Vorste, R., \& Datry, T. (2016). Invertebrate assemblage responses and the dual roles of resistance and resilience to drying in intermittent rivers. Aquatic Sciences, 78(2), 291-301.

Liancourt, P., Choler, P., Gross, N.,Thibert-Plante, X. and Tielbörger, K, 2012. How Facilitation May Interfere with Ecological Speciation. International Journal of Ecology, doi:10.1155/2012/725487.

Liess M, Beketov M. 2011. Traits and stress - keys to identify community effects of low levels of toxicants in test systems. Ecotoxiccology. 20(6). 1328-1340.

Lytle DA, Poff NL. 2004. Adaptation to natural flow regimes. Trends in Ecology \& Evolution 19:94-100.

M. Glendell, C. Extence, R. Chadd, R.E. Brazier 2013. Testing the pressure-specific invertebrate index (PSI) as a tool for determining ecologically relevant targets for reducing sedimentation in streams. Freshw. Biol., 59, pp. 353-367.

MacLean, S. A., \& Beissinger, S. R. (2017). Species' traits as predictors of range shifts under contemporary climate change: A review and meta-analysis. Global Change Biology, 23(10), 4094-4105. doi:10.1111/gcb.13736 
McCluney K.E., Poff NL, Palmer MA, Thorp JH, Poole GC, Williams BS, Williams MR, Baron JS (2014) Riverine macrosystems ecology: sensitivity, resistance, and resilience of whole river basins with human alterations. Front Ecol Environ 2014; 12(1): 48-58, doi:10.1890/120367

McMullen, L. E., Leenheer, P. D., Tonkin, J. D., \& Lytle, D. A. (2017) High mortality and enhanced recovery: modelling the countervailing effects of disturbance on population dynamics, Ecology Letters, 20, 1566-1575.

McNaughton, S.J. (1977). Diversity and Stability of Ecological Communities: A Comment on the Role of Empiricism in Ecology. The American Naturalist, 111, 515-525.

Mori A, Furukawa T, Sasaki T. 2013. Response diversity determines the resilience of ecosystems to environmental change. Biological Reviews 88: 349-364.

Morin S., Lambert A.-S., Artigas J., Coquery M., Pesce S. (2012) Diatom immigration drives biofilm recovery after chronic copper exposure. Freshwater Biology 57, 1658-1666.

Múrria, C., Bonada, N., Arnedo, M.A., Zamora-Muñoz, C., Prat, N., Vogler, A.P., 2012. Phylogenetic and ecological structure of Mediterranean caddisfly communities at various spatio-temporal scales. Journal of Biogeography, 39, 1621-1632.

Müller, F., Bergmann, M., Dannowski, R., Dippner, J. W., Gnauck, A., Haase, P., ... Theuerkauf, M. (2016). Assessing resilience in long-term ecological data sets. Ecological Indicators, 65, 10-43. DOI: $10.1016 /$ i.ecolind.2015.10.066

Naiman R.J., Décamps H. \& Mcclain M.E. (2005) Riparia: ecology, Conservation, and Management of Streamside Communities. Elsevier Academic, (C2005, Amsterdam; Boston.

Nash K.L., Graham N.A.J., Jennings S., Wilson S.K. \& Bellwood D.R. (2016). Herbivore cross-scale redundancy supports response diversity and promotes coral reef resilience. Journal of Applied Ecology, 53, 646-655.

Nimmo DG, Mac Nally R, Cunningham SC, Haslem A, Bennett AF. 2015. Vive la résistance: reviving resistance for 21st century conservation. Trends in Ecology \& Evolution 30:516-523.

Oliver, T.H., Heard, M.S., Isaac, N.J.B., Roy, D.B., Procter, D., Eigenbrod, F. et al. (2015). Biodiversity and Resilience of Ecosystem Functions. Trends in Ecology \& Evolution, 30, 673-684. 
Ormerod, S. J. and Durance, I. (2009), Restoration and recovery from acidification in upland Welsh streams over 25 years. Journal of Applied Ecology, 46: 164-174. doi: 10.1111/j.13652664.2008.01587.x

Passy, S.I. 2007. Diatom ecological guilds display distinct and predictable behavior along nutrient and disturbance gradients in running waters. Aquatic Botany 86: 171-178.

Pauls, S.U., Graf, W., Haase, P., Lumbsch, H.T., Waringer, J., 2008. Grazers, shredders and filtering carnivores - The evolution of feeding ecology in Drusinae (Trichoptera: Limnephilidae): Insight from a molecular phylogeny. Molecular Phylogenetics and Evolution, 46, 776-791.

Pedersen EJ, Marleau JN, Granados M, Moeller HV, Guichard F. 2016. Nonhierarchical Dispersal Promotes Stability and Resilience in a Tritrophic Metacommunity. Am Nat. 187:116-128. doi: $10.1086 / 685773$.

Peterson G, Allen CR, Holling CS. 1998. Ecological resilience, biodiversity, and scale. Ecosystems 1: 618.

Phillipsen, I.C. \& Lytle, D.A. (2013) Aquatic insects in a sea of desert: population genetic structure is shaped by limited dispersal in a naturally fragmented landscape. Ecography, 36, 731-743.

Poff, N. L. \& Ward, J. V. 1989. Implications of Streamflow Variability and Predictability for Lotic Community Structure: A Regional Analysis of Streamflow Patterns. _Canadian Journal of Fisheries and Aquatic Sciences, 46:1805-1818.

Poff, N.L., Olden, J.D., Vieira, N.K.M., Finn, D.S., Simmons, M.P., Kondratieff, B.C., 2006. Functional trait niches of North America lotic insects: traits-based ecological application in light of phylogenetic relationships. Journal of the North American Benthological Society, 25, 730-755.

Poff, N. L., Larson, E. I., Salerno, P. E., Morton, S. G., Kondratieff, B. C., Flecker, A. S., Zamudio, K. R., Funk, W. C. and Jeyasingh, P. (2018), Extreme streams: species persistence and genomic change in montane insect populations across a flooding gradient. Ecol Lett, 21: 525-535. doi:10.1111/ele.12918

Poole, G.C. (2002). Fluvial landscape ecology: addressing uniqueness within the river discontinuum. Freshwater Biology, 47, 641-660. 
Pulliam R.H. (1988). Sources, Sinks, and Population Regulation. H. Ronald. American Naturalist, 132, $652-661$.

Pyne, M.I. \& Poff, N.L. (2017). Vulnerability of stream community composition and function to projected thermal warming and hydrologic change across ecoregions in the western United States. Global Change Biology, 23, 77-93.

Radinger, J., Essl, F., Hölker, F., Horký, P., Slavík, O., Wolter, C. 2017. The future distribution of river fish: The complex interplay of climate and land use changes, species dispersal and movement barriers. Global change biology, 10.1111/gcb.13760

Resh, V. H., A. V. Brown, A. P. Covich, M. E. Gurtz, H. W. Li,G. W. Minshall, S. R. Reice, A. L. Sheldon, J. B. Wallace, and R. C. Wissmar. 1988. The role of disturbance in stream ecology. Journal of the North American Benthological Society 7:433-455.

Richardson J.S. \& Sato T. (2015). Resource subsidy flows across freshwater-terrestrial boundaries and influence on processes linking adjacent ecosystems. Ecohydrology, 8, 406-415.

Rinaldi, M., Surian, N., Comiti, F., \& Bussettini, M. (2015). A methodological framework for hydromorphological assessment, analysis and monitoring (IDRAIM) aimed at promoting integrated river management. Geomorphology, 251, 122-136. doi:https://doi.org/10.1016/j.geomorph.2015.05.010

Saito, V.S., Cianciaruso, M.V., Siqueira, T., Fonseca-Gessner, A.A., Pavoine, S., 2016. Phylogenies and traits provide distinct insights about the historical and contemporary assembly of aquatic insect communities. Ecology and Evolution, 6(9), 2925-2937.

Scheffer,M., Carpenter, S.R., Dakos, V. and van Nes, E.H. 2015. Generic indicators of ecological resilience: inferring the chance of critical transition. Annu. Rev. Ecol. Evol. Syst. 46: 145-167.

Scherrer, D. \& Körner, C. 2011. Topographically controlled thermal-habitat differentiation buffers alpine plant diversity against climate warming. Journal of Biogeography, 38, 406-416.

Soininen J, Bartels P, Heino J, Luoto M, Hillebrand H (2015) Toward a more integrated ecosystem research in aquatic and terrestrial environments. BioScience, 65,174-182.

Soininen, J., Jamoneau, A., Rosebery, J. \& Passy, S.I. 2016. Global patterns and drivers of species and trait composition in diatoms. Global Ecology and Biogeography 25: 940-950 
Stachowicz, J.J. 2001. Mutualism, Facilitation, and the Structure of Ecological Communities: Positive interactions play a critical, but underappreciated, role in ecological communities by reducing physical or biotic stresses in existing habitats and by creating new habitats on which many species depend. BioScience, 51: 235-246.

Statzner, B., Dolédec, S. and Hugueny, B. (2004), Biological trait composition of European stream invertebrate communities: assessing the effects of various trait filter types. Ecography, 27: 470-488. doi:10.1111/j.0906-7590.2004.03836.x

Stoll, S., Breyer, P., Tonkin, J.D., Früh, D. \& Haase, P. (2016). Scale-dependent effects of river habitat quality on benthic invertebrate communities - Implications for stream restoration practice. Sci. Total Environ., 553, 495-503

Stubbington, R. and Datry, T. (2013), The macroinvertebrate seedbank promotes community persistence in temporary rivers across climate zones. Freshw Biol, 58: 1202-1220. doi:10.1111/fwb.12121

Tedesco, P. A., Leprieur, F., Hugueny, B., Brosse, S., Durr, H. H., Beauchard, O., Oberdorff, T. (2012). Patterns and processes of global riverine fish endemism. Global Ecology and Biogeography, 21(10), 977-987.

Thompson, R, and Townsend, C. (2006) A truce with neutral theory: local deterministic factors, species traits and dispersal limitation together determine patterns of diversity in stream invertebrates. J Anim Ecol 75:476-484.

Thrush, S. F., Hewitt, J. E., Lohrer, A. M. and Chiaroni, L. D. (2013), When small changes matter: the role of cross-scale interactions between habitat and ecological connectivity in recovery. Ecological Applications, 23: 226-238. doi:10.1890/12-0793.1

Tielbörger, K. and Kadmon, R. 2000. Temporal environmental variation tips the balance between facilitation and interference in desert plants. Ecology, 81: 1544-1553.

Tonkin, J. D., Stoll, S., Jähnig, S. C. and Haase, P. (2016), Contrasting metacommunity structure and beta diversity in an aquatic-floodplain system. Oikos, 125: 686-697. doi: 10.1111/oik.02717 
Tonkin, J.D., Stoll, S., Sundermann, A. \& Haase, P. (2014). Dispersal distance and the pool of taxa, but not barriers, determine the colonisation of restored river reaches by benthic invertebrates. Freshw. Biol., 59, 1843-1855

Tonkin, J. D., M. T. Bogan, N. Bonada, B. Rios-Touma, and D. A. Lytle. 2017. Seasonality and predictability shape temporal species diversity. Ecology, 98, 1201-1216.

Tonkin, J. D., Altermatt, F., Finn, D. S., Heino, J., Olden, J. D., Pauls, S. U., \& Lytle, D. A. (2018a) The role of dispersal in river network metacommunities: patterns, processes, and pathways, Freshwater Biology, 63, 141-163.

Tonkin, J. D., Merritt, D. M., Olden, J. D., Reynolds, L. V., \& Lytle, D. A. (2018b) Flow regime alteration degrades ecological networks in riparian ecosystems, Nature Ecology \& Evolution, 2, 86-93.

Townsend CR, Scarsbrook MR, Doledec S (1997) The intermediate disturbance hypothesis, refugia, and biodiversity in streams. Limnol Oceanogr 42:938-949

Townsend, C. R. and Hildrew, A. G. (1994), Species traits in relation to a habitat templet for river systems. Freshwater Biology, 31: 265-275. doi:10.1111/j.1365-2427.1994.tb01740.x

Uehlinger U. 2000. Resistance and resilience of ecosystem metabolism in a flood-prone river system. Freshwater Biology 45, 319-332

Van Looy, K., Meire, P. \& Wasson, J.-G. 2008. Including riparian vegetation in the definition of morphologic reference conditions for large rivers: a case study for Europe's Western Plains. Environmental Management 41: 625-639.

Van Looy K, Floury M, Ferréol M, Prieto-Montes M, Souchon Y. 2016. Long-term changes in temperate stream invertebrate communities reveal a synchronous trophic amplification at the turn of the millennium. Science of the Total Environment, 565, 481-488.

Van Looy, K., Tormos, T. \& Souchon, Y. 2014. Disentangling dam impacts in river networks. Ecological Indicators, 37, 10-20.

Weaver, J.L., P.C. Paquet, and L.F. Ruggiero. 1996. Resilience and conservation of large carnivores in the Rocky Mountains. Conservation Biology 10:964-976.

Webb, C.O., Ackerly, D.D., McPeek, M.A., Donoghue, M.J., 2002. Phylogenies and community ecology. Annual Review of Ecology and Systematics, 33, 475-505. 
Verberk, W.C.E.P., van Noordwijk, C.G.E., Hildrew, A.G., 2013. Delivering on a promise: integrating species traits to transform descriptive community ecology into a predictive science. Journal of the North American Benthological Society, 32, 531-547.

Violle, C. et al. 2014. The emergence and promise of functional biogeography. Proceedings of the National Academy of Sciences USA 111: 13690-13696.

White PS, Pickett STA (1985) Natural disturbance and patch dynamics: an introduction. In: Pickett STA, White PS (eds) The ecology of natural disturbance and patch dynamics. Academic Press, New York, pp 3-13

Wolter C., A. D. Buijse, and P. Parasiewicz 2015. Temporal and Spatial Patterns of Fish Response to Hydromorphological Processes. River Research and Applications doi:10.1002/rra.2980

Wolter, C. \& Vilcinskas, A. (1997). Perch (Perca fluviatilis) as an indicator species for structural degradation in regulated rivers and canals in the lowlands of Germany. Ecology of Freshwater Fish, 6, 174-181. doi:doi:10.1111/j.1600-0633.1997.tb00160.x

Woodward G, Bonada N, Brown LE, et al. 2015. The effects of climatic fluctuations and extreme events on running water ecosystems. Philosophical Transactions of the Royal Society B: Biological Sciences. 371. doi:10.1098/rstb.2015.0274.

Wootton T. and Emmerson M. 2005. Measurement of interaction strength in nature. Annu. Rev. Ecol. Evol. Syst. 2005. 36:419-44. doi: 10.1146/annurev.ecolsys.36.091704.175535

Yang L.H. \& Naeem S. (2008). The ecology of resource pulses. Ecology, 89, 619-620.

Yang L.H., Bastow J.L., Spence K.O. \& Wright A.N. (2008). What can we learn from resource pulses. Ecology, 89, 621-634.

Yvon-Durocher G, Allen AP, Cellamare M, Dossena M, Gaston KJ, Leitao M, Montoya JM, Reuman DC, Woodward G, Trimmer M. 2015. Five years of experimental warming increases the biodiversity and productivity of phytoplankton. PLoS Biology 13: e1002324.

Table 1. Identification of characteristic taxonomic, phylogenetic and functional traits for the three resilience mechanisms.

\begin{tabular}{|c|c|c|c|}
\hline Indices & Resources & Recruitment recovery & Refugia \\
\hline Taxonomic & Richness/abundance, & Taxonomic & Taxonomic richness \\
\hline
\end{tabular}




\begin{tabular}{llll}
\hline & Shannon diversity & beta diversity & \\
Phylogenetic & Species relatedness & Community similarity & Distinctness and diversity \\
Functional traits & $\begin{array}{l}\text { Feeding habits, trophic } \\
\text { groups }\end{array}$ & $\begin{array}{l}\text { Dispersal traits, Habitat guilds and } \\
\text { reproduction traits }\end{array}$ & \begin{tabular}{l} 
specific life history traits \\
\hline
\end{tabular}
\end{tabular}

Table 2. Identification of characteristic functional trait classifications for the three resilience mechanisms for fish (Wolter et al 2015), benthic invertebrates (Poff et al. 2006), diatoms (Passy 2007), and macrophytes (Grime 1974).

\begin{tabular}{|c|c|c|c|}
\hline Indices & Resources & Recruitment recovery & Refugia \\
\hline Fish & $\begin{array}{l}\text { feeding opportunism, } \\
\text { habitat generalist, } \\
\text { short-lived, r-strategy, } \\
\text { long spawning season; } \\
\text { batch spawning }\end{array}$ & $\begin{array}{l}\text { Fecundity, iteroparity, } \\
\text { swimming/ migration } \\
\text { ability, small bodied, } \\
\text { strong disperser }\end{array}$ & $\begin{array}{lr}\text { Habitat specialist, } \\
\text { longevity, swimming } \\
\text { performance, endemism, } \\
\text { k-strategy }\end{array}$ \\
\hline Invertebrates & Multivoltine, generalist & $\begin{array}{l}\text { Drift, crawling, } \\
\text { swimming, flight ability, } \\
\text { high fecundity }\end{array}$ & $\begin{array}{l}\text { Resistance forms, eggs, } \\
\text { shells, habitat specialist }\end{array}$ \\
\hline Diatoms & Generalists/ubiquists & $\begin{array}{l}\text { Strong dispersers } \\
\text { (flattened shape) }\end{array}$ & Resistors \\
\hline Macrophytes & C-strategy (competitor) & $\begin{array}{l}\text { R-ruderal producing } \\
\text { many seeds, seed } \\
\text { banks, buoyancy }\end{array}$ & $\begin{array}{l}\text { S-stress tolerator- } \\
\text { resistor, habitat specialist }\end{array}$ \\
\hline
\end{tabular}




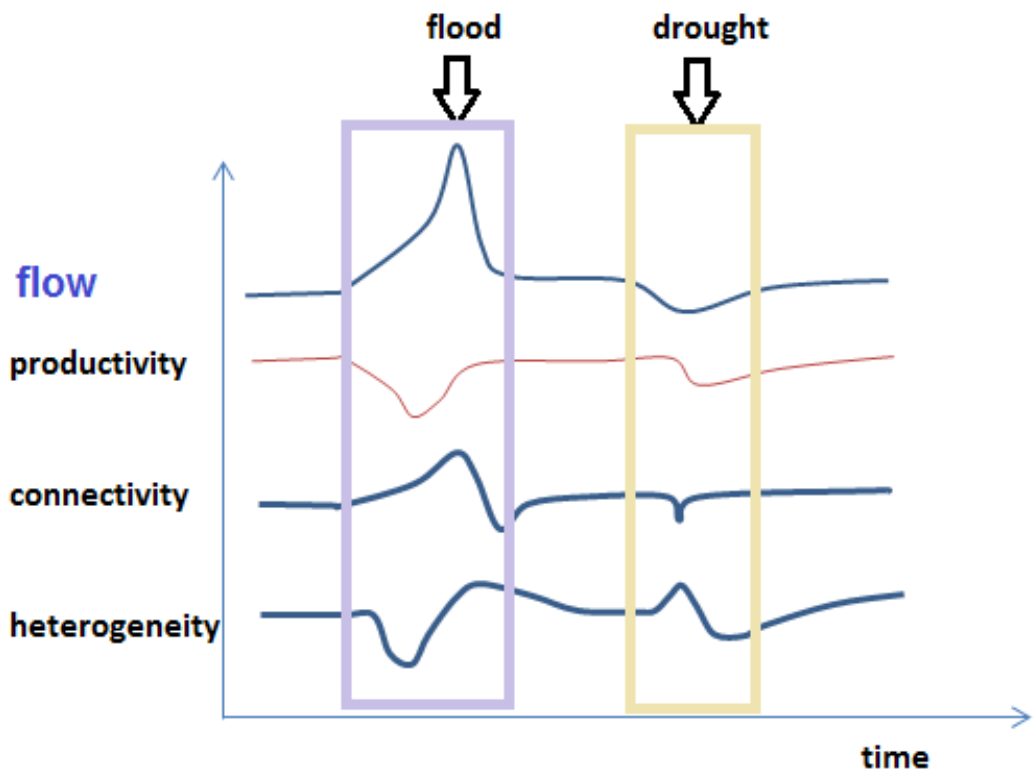

Figure 1. River disturbances induced by high ("flood") and low ("drought") flows, and potential effects on three distinguished ecosystem properties (based on published works referred to in the text).

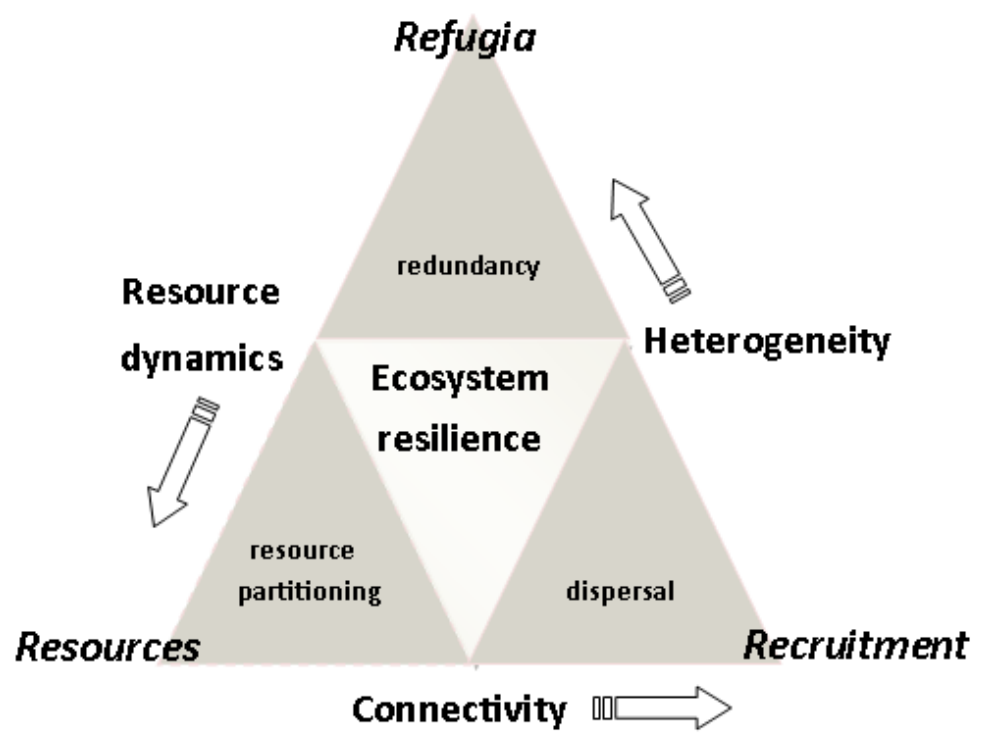

Figure 2. Conceptual river resilience framework representing the three mechanisms driving resilience of communities: resource competition/facilitation, dispersal-based recruitment recovery and refuge-mediated functional redundancy. The extrinsic drivers at the ecosystem scale (arrows) that steer the prevalence of specific mechanisms are resource dynamics, landscape connectivity and environmental heterogeneity. 


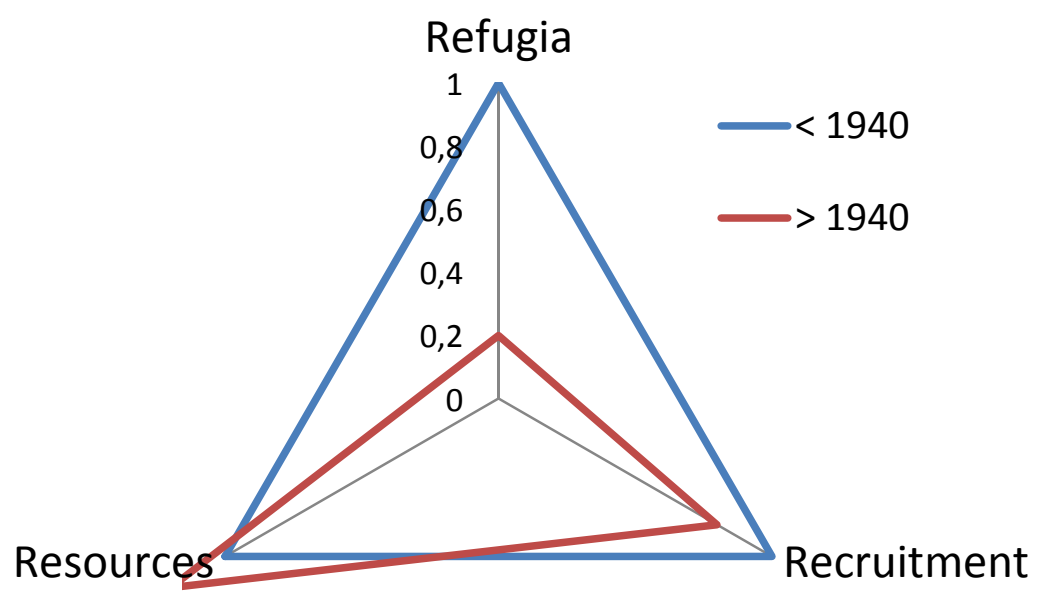

Figure 3. Illustrative Radar chart presentation of the resilience of the Upper Mississippi River communities of fish before and after the construction of the locks and dams (example 2 in Box). The post-1950 resilience surface is strongly reduced due to diminished functional diversity.

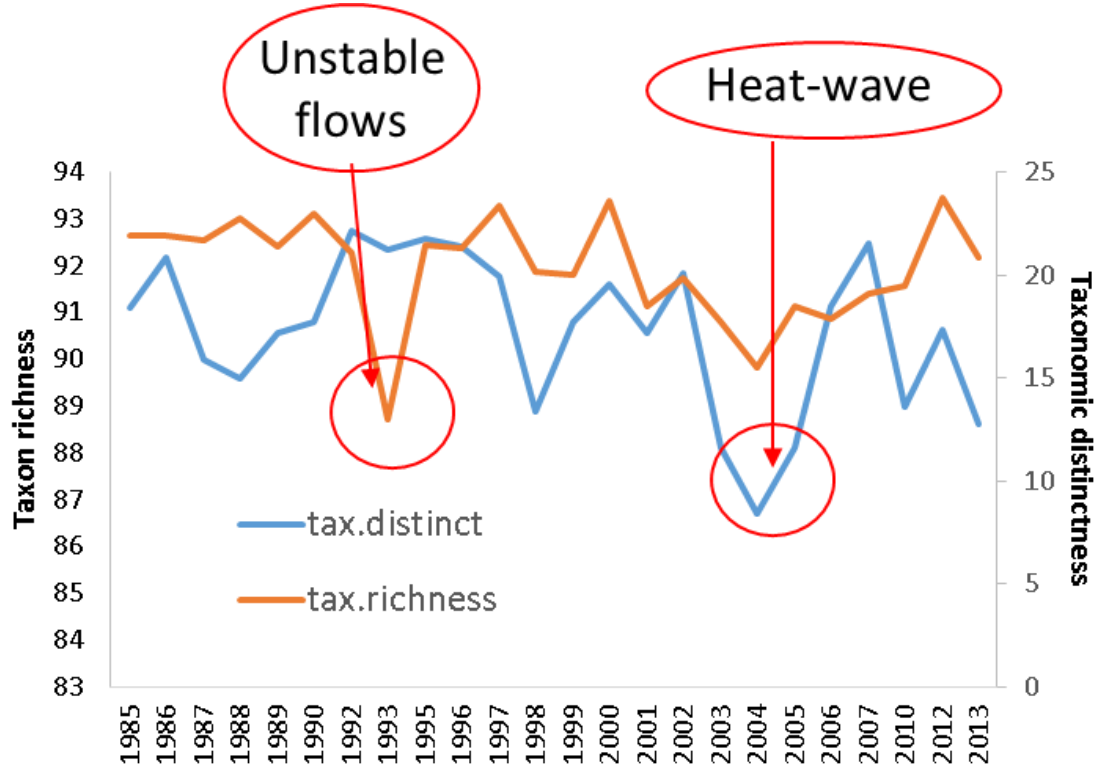

Figure 4. Temporal pattern of taxonomic richness and distinctness from a 28-year study of benthic invertebrates at 10 streams in the Lynn Brianne Stream Observatory. Taxonomic distinctness is based on the phylogenetic affiliation among taxa (increasing distinctness indicates assemblages with more phylogenetically distant taxa). 


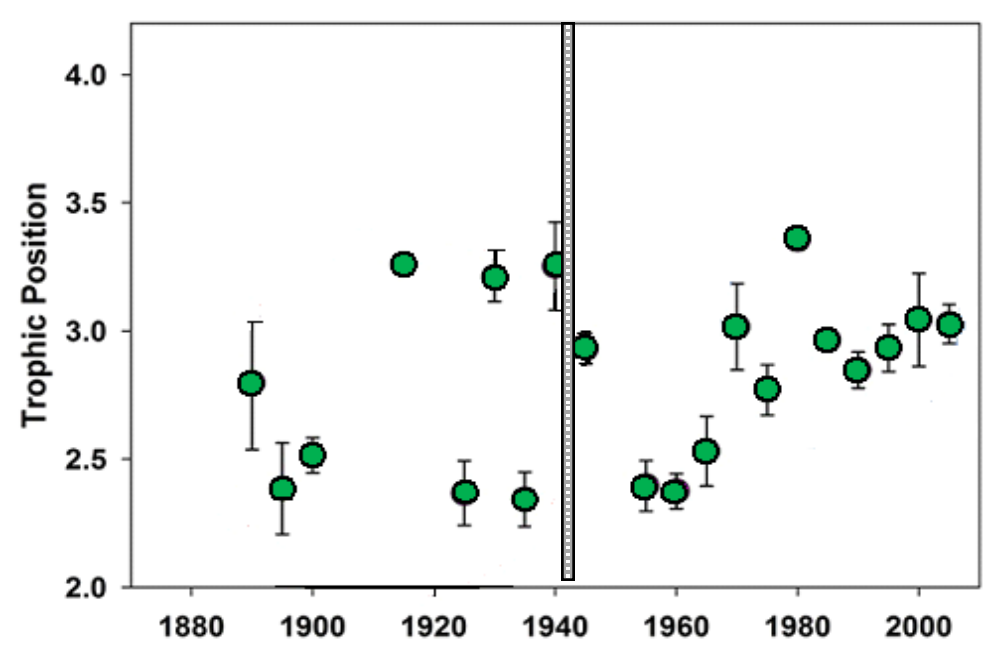

Figure 5. The loss of natural fluctuations in the ecosystem leads to a resilience loss, illustrated in the reduced inter-annual variance in trophic position of fish guilds (loss of natural fluctuations in trophic position of community; mean $+S D$ ). The mean trophic position of fish over the last century illustrates the reduced inter-annual variance in trophic position of fish guilds related to changes in hydrology of the Upper Mississippi River. The ecosystem responds to flow regime modifications around 1940, with loss of functional diversity/variability and thus loss of resilience observed in the loss of capacity to respond to changes in hydrological conditions.

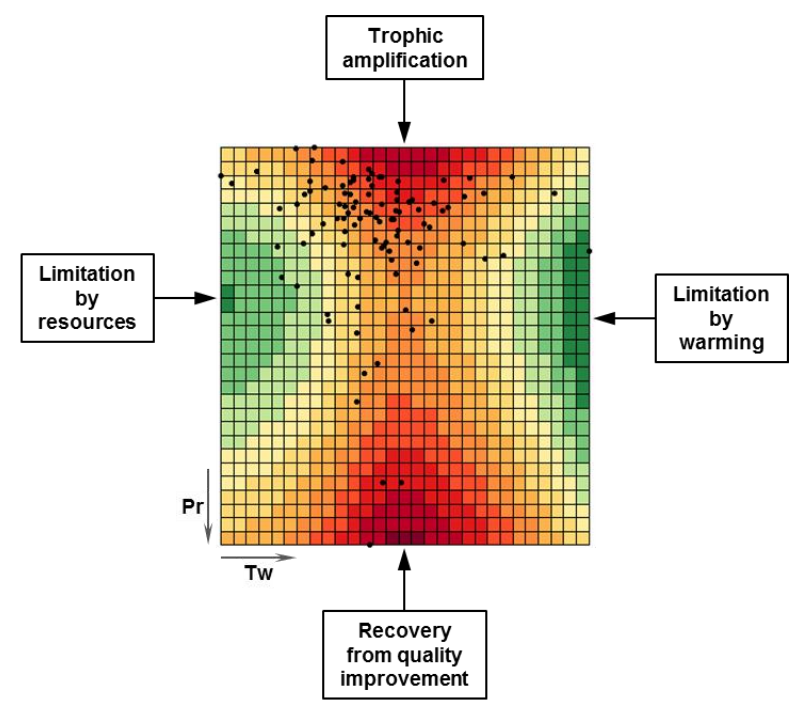

Figure 6. Changes in feeding specialization of invertebrate communities in response to long-term trends in phosphate concentration ( $P r$ - Phosphate reduction) and temperature ( $T w$ - temperature warming), for a regional long-term dataset (Auvergne-Rhône-Alpes, France, $n=100$ sites, 20 years). Green grid cells are associated with a decrease in feeding specialization whereas yellow-to-red colours represent gradual increases in feeding specialization. 